\title{
Evaluation of Optimized 3-step Global Reaction Mechanism for CFD Simulations on Sandia Flame D
}

\author{
Department of Applied Mechanics, \\ Chalmers University of Technology \\ Gothenburg, Sweden
}

Abdallah Abou-Taouk and Lars-Erik Eriksson

\begin{abstract}
The aim of this paper is to evaluate a new optimized 3-step global reaction mechanism (opt) [1] for a methaneair mixture for industry purpose. The global reaction mechanism consists of three reactions corresponding to the fuel oxidation into $\mathrm{CO}$ and $\mathrm{H}_{2} \mathrm{O}$, and the $\mathrm{CO}-\mathrm{CO}_{2}$ equilibrium reaction. Correction functions that are dependent on the local equivalence ratio are introduced into the global mechanism. The optimized 3-step global reaction scheme is adapted into the Computational Fluid Dynamics (CFD) analysis of a partially-premixed piloted methane jet flame. The burner consists of a central nozzle (for premixed fuel/air), surrounded by a premixed pilot flame, and an annular co-flow stream. Both steady-state RANS (Reynolds Averaged Navier Stokes) and time-averaged hybrid URANS/LES (Unsteady RANS/Large Eddy Simulation) results have been computed and compared with experimental results obtained from the Sydney burner at Sandia National Laboratories, Sandia Flame D [2]. The CFD results with the optimized 3-step global reaction mechanism show reasonable agreement with the experimental data based on emission, velocity and temperature profiles, while the 2-step Westbrook Dryer (WD2) [3] global reaction mechanism shows poor agreement with the emission profiles.
\end{abstract}

Keywords: CFD, PSR, global mechanism, combustion, methane-air mixture, WD2

PACS: $47.70 . P q$

\section{INTRODUCTION}

A demand on reduced emissions and improved efficiency for the gas turbine combustors implies that reliable and accurate modelings of chemical kinetics are crucial. In reality detailed reaction mechanisms for hydrocarbon combustion are extremely complex since they involve around 100 species and 10000 reactions. Some detailed mechanisms of methane-air combustion involve more than 300 elementary reactions and over 30 species [4]. From a CFD perspective it is still too expensive to include all species and reactions. The use of global reaction mechanisms is one way to go for CFD simulations, since they are easily implemented in commercial software. Several different reduced reaction mechanisms of methane-air mixtures exist in the literature [5-7]. The drawback of most of the published global mechanisms is that they are not flexible enough to cope with a wide range of equivalence ratios. The presently used optimized 3-step global reaction mechanism (opt) has been developed for equivalence ratios in the range $0.5-1.8$ and at atmospheric pressure [1].

The WD2 global reaction mechanism [3] is commonly seen in the literature and is an old industry standard for CFD simulations. The drawback with the WD2 is due to the poor emission prediction at rich conditions since it produces too much $\mathrm{CO}_{2}$ and not enough carbon monoxide compared to the detailed reaction mechanism. LES simulations by Pitsch et al. [8] show very good agreement with the experimental data. However, the mesh size is three times larger and the time step is ten time smaller than the SAS-SST model, which implies that the computational time is very expensive. The aim of the present work is to improve, validate and evaluate current standard industrial CFD tools. It is too expensive for the industry to run LES in their daily work. In the CFX validation report [9] the conclusion is that the RNG k- $\varepsilon$ model together with the WD2 model works well for industry purpose. CFD simulation with the same settings as in the CFX validation report [9] has been performed and used for comparisons in the present work (RNG k- $\varepsilon$ WD2). The results obtained agree well with those given in the CFX validation report. So, no improvements or modifications have been done for the RNG k- $\varepsilon$ WD2. The improvements of the predictions of the emissions are seen by the 3-step global reaction mechanism since the optimized mechanism increases the reaction rate on the first reaction to increase the $\mathrm{CO}$ production. Simultaneously, the second reaction rate is reduced, thus oxidizing less $\mathrm{CO}$ and therefore less $\mathrm{CO} 2$ is produced.

Numerical Analysis and Applied Mathematics ICNAAM 2011

AIP Conf. Proc. 1389, 66-69 (2011); doi: 10.1063/1.3636672

(C) 2011 American Institute of Physics 978-0-7354-0956-9/\$30.00 


\section{KINETIC MODELING}

The optimized 3-step global reaction mechanism consists of the reactions seen in table 1 . The first reaction is the oxidation of methane into $\mathrm{CO}$ and $\mathrm{H}_{2} \mathrm{O}$ and the second reaction is the oxidation of $\mathrm{CO}$ into $\mathrm{CO}_{2}$. The backward rate for the second reaction is based on an equilibrium assumption. Table 1 also shows the optimized Arrhenius coefficients (activation energy, pre-exponential factor and temperature coefficient) that are used in the 3-step global reaction mechanism.

TABLE 1. Activation energy $E_{a}$, pre-exponential factor $A$ and temperature coefficient $\beta$ used for the optimized scheme.

\begin{tabular}{lclr}
\hline Reaction & A & Ea [J/kmol] & \multicolumn{1}{c}{$\boldsymbol{\beta}$} \\
\hline $2 \mathrm{CH}_{4}+3 \mathrm{O}_{2} \rightarrow 2 \mathrm{CO}+4 \mathrm{H}_{2} \mathrm{O}$ & $1.398762 \mathrm{e} 10$ & $1.16712 e 8$ & -0.062 \\
$2 \mathrm{CO}+\mathrm{O}_{2} \leftrightarrow 2 \mathrm{CO}_{2}$ & $7.381123 \mathrm{e} 11$ & $7.65969 e 7$ & 0.215 \\
\hline
\end{tabular}

The backward rate for the second reaction is based on an equilibrium assumption and the reaction rates for the forward reactions are the following:

$$
\begin{aligned}
& R R_{1}=f_{1}(\varnothing) T^{\beta_{1}} A_{1} e^{\frac{-E_{a 1}}{R T}}\left[\mathrm{CH}_{4}\right]^{0.5}\left[\mathrm{O}_{2}\right]^{1.066} \\
& R R_{2}=f_{2}(\varnothing) T^{\beta_{2}} A_{2} e^{\frac{-E_{a 2}}{R T}}\left[\mathrm{CO}_{2}\right]^{2}\left[\mathrm{O}_{2}\right]^{1}
\end{aligned}
$$

where $A$ is the pre-exponential factor, $E_{a}$ is the activation energy, $R$ is the gas constant, $T$ is the temperature and $f_{1}$ and $f_{2}$ are the correction functions. The aim of these correction functions is to ensure good agreement for rich conditions. Franzelli at al. [10] optimized similar correction functions, but for kerosene fuel ant therefore one expect to see some differences in the shape of these functions for methane air-mixture, which can be seen to the left in Figure 1. The 3-step global reaction mechanism is optimized against a detailed reference mechanism (GRI Mech 3.0) for perfectly stirred reactor (PSR) calculations [1]. The CANTERA software has been used for the detailed mechanism simulations and an in-house PSR code for the global reaction mechanism. In a comparison of the optimized 3-step global reaction mechanism with the reference detailed reaction mechanism, the results show that the gas temperature and emissions are reasonably well predicted for lean and rich conditions [1]. Figure 1 shows also the temperature predictions at different equivalence ratios.
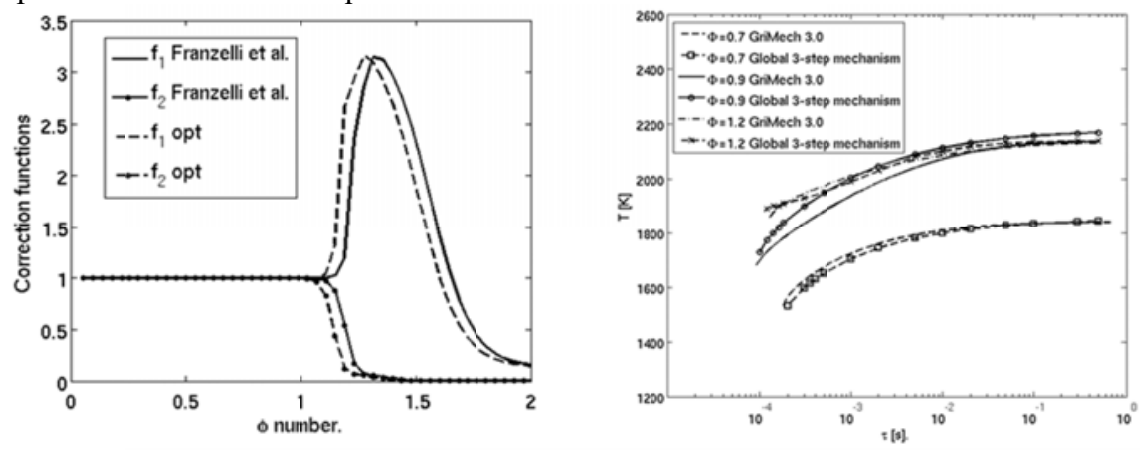

FIGURE 1. Left: Plot showing the correction functions $f_{1}$ and $f_{2}$ between Franzelli at al. [8] (for kerosene fuel) and AbouTaouk et al. [1] (methane-air mixture). Right: Plot showing temperature comparisons of a detailed mechanism (Gri Mech 3.0) and optimized 3-step global mechanism for methane-air gas mixture at equivalence ratios of $0.7,0.9$ and 1.2 , Tin=295K

\section{CFD Analysis}

The Ansys CFX software package [11] was used as a solver. The RNG k-epsilon turbulence model was selected for the steady-state simulations and SAS-SST model for the transient simulation. Two different global reaction schemes were used for the CFD simulations, the optimized 3-step global reaction mechanism [1] and the WD2 global reaction mechanism [3]. The combined turbulence-chemistry interaction model, the Finite Rate Chemistry/ Eddy Dissipation Model (FRC-EDM), in Ansys CFX [11], was chosen for all CFD analyses. The combined FRCEDM model gives two different reaction rates for each reaction, one from the EDM model and one from the FRC model. The minimum rate for each reaction is then chosen. The EDM model is based on the work of Magnussen and Hjertager [12]. 
The Sandia Flame D consists of a main jet with a mixture of $25 \%$ of methane and $75 \%$ of air. This jet is located in a co-flowing gas stream of air and the flame is stabilized by a pilot. Experimental data from the Technical University of Darmstadt [2] is used to set temperature, species mass fractions, turbulence and velocity profiles at the inlet boundaries. All CFD simulations were done on a $360^{\circ}$ model. The mesh size for the RANS simulations were $0.5 \mathrm{M}$ cells and $3.5 \mathrm{M}$ cells for the transient simulation.

\section{Results}

Figure 2 shows plots of axial profiles of mass fraction (computed and experimental) of $\mathrm{CH}_{4}, \mathrm{CO}_{2}$ and $\mathrm{CO}$ respectively. The WD2 global reaction mechanism over-predicts $\mathrm{CO}_{2}$ and under-predicts $\mathrm{CO}$ at all positions. The 3step optimized global reaction mechanism shows reasonable agreement between the experimental data and the simulations considering the $\mathrm{CH}_{4}$ and $\mathrm{CO}_{2}$. However, the $\mathrm{CO}$ level is over-predicted..
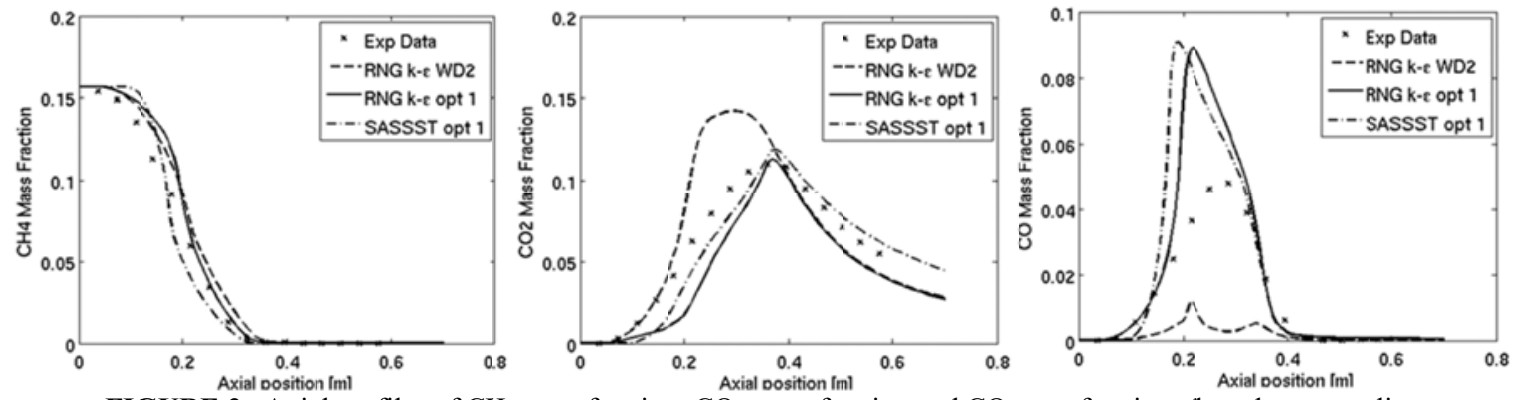

FIGURE 2. Axial profiles of $\mathrm{CH}_{4}$ mass fraction, $\mathrm{CO}_{2}$ mass fraction and $\mathrm{CO}$ mass fraction plotted at center line

Figure 3 shows plots of radial profiles of mass fraction (computed and experimental) of $\mathrm{CH}_{4}, \mathrm{CO}_{2}$ and $\mathrm{CO}$ respectively for different axial positions. Similar as before, the WD2 global reaction mechanism over-predicts $\mathrm{CO}_{2}$ and under-predicts $\mathrm{CO}$ at radial positions. The 3-step optimized global reaction mechanism shows reasonable agreement considering the $\mathrm{CH}_{4}$ and $\mathrm{CO}_{2}$. However, similar to the previously plot, the $\mathrm{CO}$ level is over-predicted.
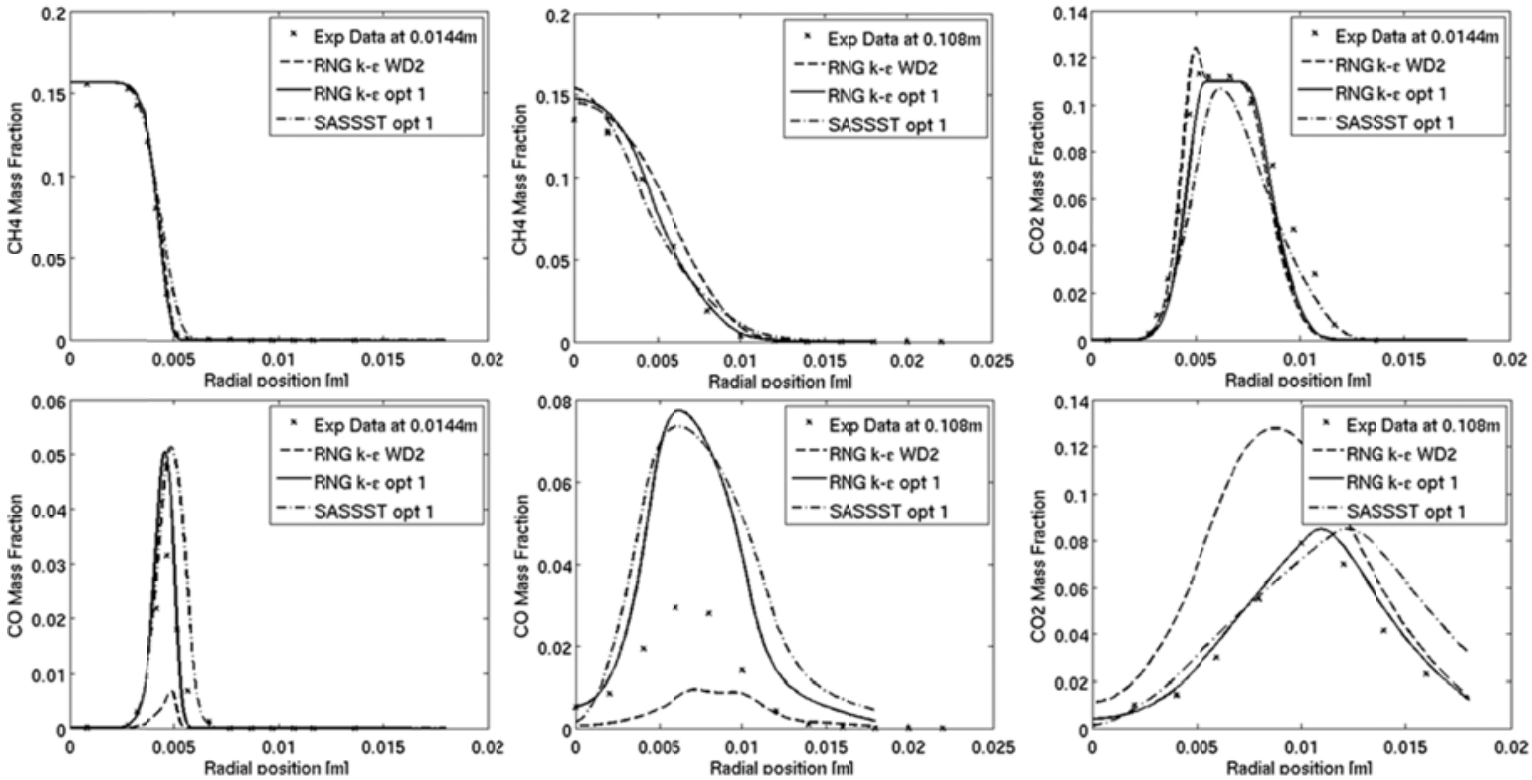

FIGURE 3. Radial profiles of $\mathrm{CH}_{4}$ mass fraction plotted at axial positions $0.0144 \mathrm{~m}$ and $0.108 \mathrm{~m}, \mathrm{CO}_{2}$ mass fraction plotted at axial positions $0.0144 \mathrm{~m}$ and $0.108 \mathrm{~m}, \mathrm{CO}$ mass fraction plotted at axial positions $0.144 \mathrm{~m}$ and $0.108 \mathrm{~m}$ 
Figure 5 shows radial/axial temperature profiles and axial profile of the axial velocity. It can be seen that there is generally reasonable agreement between the experimental data and the simulations. The temperatures are generally over predicted close to the inlets of the burner and well predicted downstream of the burner. A reasonable explanation of this is due to that the radiation is not included in the CFD-simulations. The axial velocity is also well predicted. The transient simulation (SAS-SST) captures the temperature and the velocity profiles better downstream than the steady-state simulations.
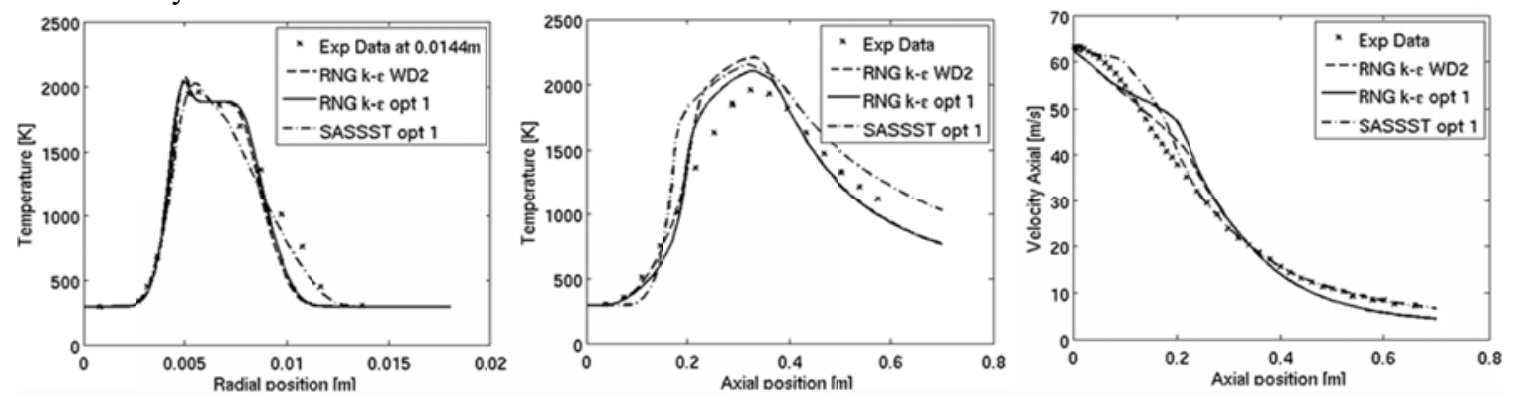

FIGURE 4. Left: Radial profile of static temperature $[\mathrm{K}]$ plotted at axial position $0.3240 \mathrm{~m}$, Middle: Axial profile of static temperature $[\mathrm{K}]$ plotted at center line, Right: Axial profile of axial velocity $[\mathrm{m} / \mathrm{s}]$ plotted at center line

\section{CONCLUSIONS}

An optimized 3-step global reaction mechanism for methane-air mixtures is evaluated and applied in CFD analyses. The Sandia Flame D has been modeled with the optimized 3-step scheme and WD2 using CFD tools. The CFD results with the 3-step global reaction mechanism show reasonable agreement with the experimental data based on emission, velocity and temperature profiles, while the 2-step WD2 global reaction mechanism shows poor agreement with the emission profiles.

\section{ACKNOWLEDGMENTS}

This research has been funded by the Swedish Energy Agency, Siemens Industrial Turbomachinery AB, Volvo Aero Corporation, and the Royal Institute of Technology through the Swedish research program TURBOPOWER, the support of which is gratefully acknowledged.

\section{REFERENCES}

1. A. Abou-Taouk and L.E Eriksson, 2011, "Optimized Global Mechanisms For CFD Analysis Of Swirl-Stabilized Syngas Burner For Gas Turbines", ASME Turbo Power Expo, Power for land, Sea and Air, GT2011-45853.

2. Sandia National Laboratories, Turbulent Diffusion Flame Laboratory Web Site, http://www.ca.sandia.gov/tfd

3. Charles K. WestBrook and Frederick L. Dryer, 1984, "Chemical Kinetic Modeling of Hydrocarbon Combustion", Prog. Energy Combustion Sci. 1984, Vol. 10, pp. 1-57.

4. Y. Liu, K. S. Lau, C. K. Chan, Y. C. Guo, W. Y. Lin, "Structures of Scalar Transport in 2D Transitional Jet Diffusion Flames by LES”, Int. J. Heat Mass Tran. 46, 3841-3851 (2003).

5. Karl V. Meredith and David L. Black, 2006, "Automated Global Mechanisms Generation for use in CFD Simulations", AIAA 2006-1168.

6. N. Slavinskaya, M. Braun-Unkhoff and P.Frank, 2008, "Reduced Reaction Mechanisms for Methane and Syngas Combustion in Gas Turbines", Journal of Engineering for Gas Turbines and Power, Vol.130'

7. M P. Gokulakrishnan, S. Kwon, A.J. Hamer, M.S. Klassen and R..J. Roby, 2006, "Reduced Kinetic Mechanism for Reactive Flow Simulation of Syngas/Methane Combustion at Gas Turbine Conditions, ASME Turbo Power Expo, Power for land, Sea and Air, GT2006-90573

8. H. Pitsch and H. Steiner, 2000, "Large-eddy simulation of a turbulent piloted methane/air diffusion flame (Sandia flame D)", Phys. Fluids 12, 2541-2555.

9. D. Gobby, "Piloted methane jet flame", 2009.

10. B. Franzelli, E. Riber, M. Sanjose and T. Poinsot, 2010, “A two-step chemical scheme for kerosene-air flames", Combustion and Flame 175:1364-1373.

11. Commercial software Ansys CFX, http://www.ansys.com/default.asp

12. B. F. Magnussen and B. H. Hjertager. "On mathematical models of turbulent combustion with special emphasis on soot formation and combustion". 16th Symp. (Int'1.) on Combustion. The Combustion Institute, 1976. 